\title{
Evaluation of the Biocompatibility and Graft Integration Following Ligamentoplasty or Augmentation Experimental study on rabbits
}

\author{
CLAUDIU CHITEA ${ }^{1}$, GHEORGHE TOMOAIA ${ }^{1}$, OANA D. TOADER ${ }^{2 *}$, CLAUDIA MILEA ${ }^{3}$, OCTAVIAN TRANTE $^{3 *}$, KAMEL EARAR ${ }^{4}$, \\ VICENTIU SACELEANU 5 \\ Iuliu Hatieganu University of Medicine and Pharmacy, 8 Victor Babes Str., 400012, Cluj Napoca, Romania \\ ${ }^{2}$ Carol Davila University of Medicine and Farmacy, 37 Dionisie Lupu Str., 030167, Bucharest, Romania \\ ${ }^{3}$ Politehnica University of Bucharest, Faculty of Materials Science and Engineering, 313 Splaiul Independentei, 060042, Bucharest, \\ Romania \\ ${ }^{4}$ Dunarea de Jos University of Galati, Medicine and Pharmacy Faculty, Departament of Dentistry, 47 Domneasca Str., 800008, \\ Galati, Romania \\ EUniversity Lucian Blaga, Faculty of Medicine, 2A Lucian Blaga Str., 550169, Sibiu, Romania
}

\begin{abstract}
Several techniques are used to reconstruct the anterior cruciate ligaments $(A C L)$ by using different grafts in order to obtain a new ligament with properties closest to those of the healthy one. Our aim was a faster graft harvesting and the integration into the bone tissue; we have studied the efficiency of the techniques that preserve the torn ligament end vs. the techniques that used a graft harvested from the patient. The ligamentoplasty studies performed on rabbits reveal a satisfactorily cost-efficiency ratio, this being the main reason for choosing this model. We wanted to study the importance of preserving one edge of the torn ligament as a base of integration for the new graft and compare the appearance of the blood vessels and the neoformation tissue in the two study groups. For the first study group we performed an implantation technique that uses a complete new graft harvested from the same animal and for the second group we used the technique which preserves the torn ligament. All the surgical procedures were conducted on the NZW rabbits. All ligamentoplasty reconstruction surgical interventions were conducted on the left limb and the graft was harvested from the extensori digitorum longi located on the lateral side of the rabbit's thigh. Twelve rabbits in each group were operated upon using the two techniques and the results were compared. No major complications were noted, the long term results were similar, and with no significant differences as far as the ligament integration was concerned. The study group in which the ligament end was preserved showed a more rapid integration. Our study suggests that keeping a longer ligament end correlates with early graft integration.
\end{abstract}

Keywords: graft, ligamentoplasty, biocompatibility, rabbit, suture, polydioxanone

The aspects regarding biomaterials applications are very important in orthopedic surgery for various directions like trauma implant [1, 2], joint prosthesis [3], ligament reconstruction $[4,5]$, bone substitutes [6], bone cements [7-9], and bone tissue engineering [10-13], Also, in the last years it's available a large number of the researches who deals with novel specific aspects from biocompatibility of the suture materials and polymeric devices [14-17].
The anterior cruciate ligament lesion represents the most frequent ligament lesions which require a reconstruction surgery. Young people who practice recreational or professional sports are often affected.

The anterior cruciate ligament lesion modifies the knee dynamic which produces instability and a functional impairment due to pain [18]. In addition, these lesions will lead to arthrosis and meniscus lesion.
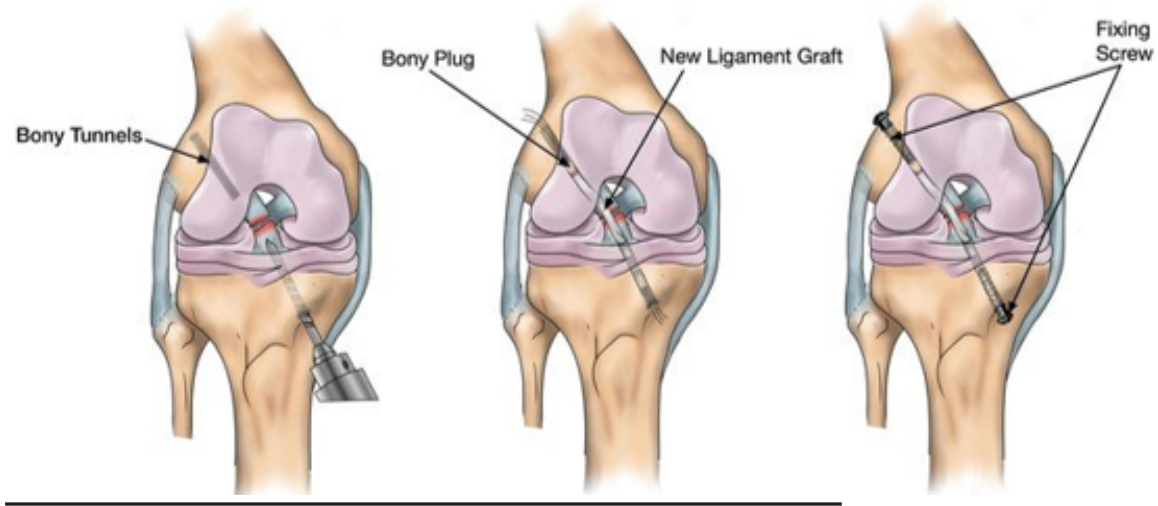

Fig. 1. Schematic view of the anterior cruciate ligament reconstruction

* emasil: oana.toader@yahoo.com, tranteoctavian@yahoo.com 
Different tendon grafts are used for the reconstruction of the anterior cruciate ligament and for its attachment several versions of holding systems are available (interference screw, variable or fixed loop buttons or staples).

The need for $A C L$ surgical reconstruction is justified by the $A C L$ anatomical characteristics. Unfortunately, ligament reconstruction cannot recreate the similar properties of a native $A C L$ from the anatomical, biological, biomechanical and neurophysiological point of view [1921].

An ideal graft used for surgical $A C L$ reconstruction should be one that recreates the anatomical and biomechanical properties of the native ligament. That means the assurance of the ligament fixation and rapid biological integration, reducing recovery time. Different autogenous, allogenic and synthetic grafts have been suggested to be used, to date none meet all the criteria previously described [22,23].

The use of allogenic tissues has become more popular in recentyears due to the advantages like a shorter surgical time, the possibility of using any type of graft, and quicker patient recovery. The disadvantages include the risk of transmission of infectious diseases, delay in the remodeling and integration processes due to the sterilization methods.

When choosing a graft we must include the potential for bone integration and the risk of failure. Bone sclerosis that occurs around the tunnel affects the integration of the graft. For this reason, the biology of the graft involved is one of the aspects which orthopedic surgeons should evaluate closely. From this perspective, the choice of BPTB graft appears somewhat contradictory.

Although numerous studies have been conducted to date, entheses cannot yet be restored with any surgical technique. The all-inside technique is a minimally invasive surgical technique that uses a single tendon and preserves both the proprioceptive and the biomechanical system of the knee. It restores stability in both anterior and rotational loading of the knee. Other benefits include less bone loss and quicker ligamentization, limited esthetic damage, and a low risk of infection. The all-inside technique is characterized by two half-tunnels created by in-out manual milling; this, reducing the thermal stress on the bone, reduces necrotic processes and increases the release of growth factors which enhance the fibroblastic and osteoblastic activity that facilitates graft integration.
The long term success rate depends on: the accuracy of the surgical technique, the post-surgical recovery process and the graft integration in the bone tunnel.

Thus, the improvement of the graft integration process remains a real challenge.

For this purpose there have been used a number of animal models with slight differences among them: sheep, goats, pigs, dogs and rabbits. Some difficulties appear when large animals are studied (goats, sheep, dogs, pigs), such as nursing in large spaces, special equipment, the manipulation of the animals during the experiments, a difficult anaesthetic procedure and the expensive price of these animals. Thus, a viable option is performing the studies on smaller animals, such as rabbits, with better cost-efficiency ratio.

Suture threads can be:

- absorbable or non-absorbable

- monofilament or multifilament

- synthetic or natural

The most common manufacturing materials for synthetic absorbable threads are: polymers of glycolic acid and polydioxanone.

Resorbable multifilament sutures such as PLA and PGA develop a greater amount of friction when penetrating tissues and have a higher risk of infection. So, monofilament sutures based on PDO having smooth and soft surface were introduced in the 1980s. PDO suture has handling properties that are acceptable for use in vascular applications, and itprovides adequate mechanical support for sutured vessels to heal. In addition, PDO provides good flexibility owing to the presence of an ether oxygen group in the backbone of the polymer chain.

Suture threads should have the following properties: tear resistance, tissue support, minimal tissue effect (easy passage without traumatic tissue tearing), easy handling, increased flexibility, safe tying, reduced capillarity (low bacterial growth).

PDO would appear to be particularly useful in situations requiring extended wound support, in potentially infected

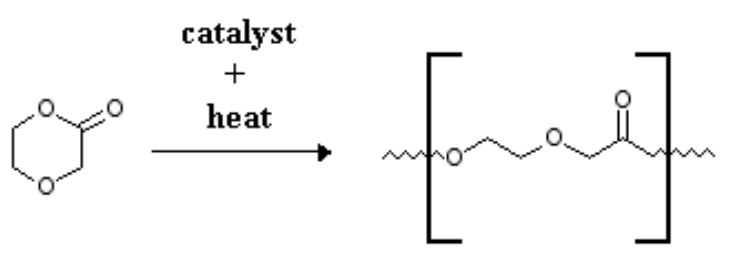

p-dioxanone

Fig. 2. Ring opening polymerization of $p$-dioxanone to polydioxanone

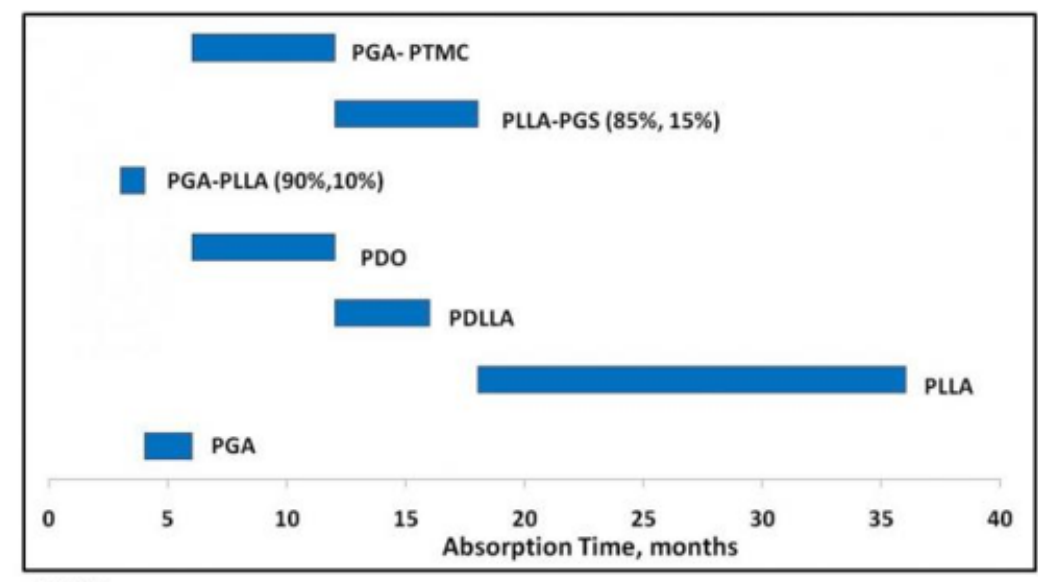

Fig. 3. Absorption time of bioresorbable materials

LEGEND

PGA-PTMC $=$ Polyglycolic Acid - Poly-Tri-Methylene-Carbonate PLLA-PGS $=$ Poly L-Lactide Acid $/$ Poly Glycerol Sebacate PGA-PLLA = Poly Glycolic Acid / Poly L-Lactic Acid PDO $=$ Polydioxanone
POLLA $=$ Poly - DL-Lactic Acid

$P L A=$ Poly - L-Lactic Acid PGA $=$ Poly Glycolic Acid 
wounds in which a monofilament suture would have lessened tendency to harbor pathogenic bacteria, and in cases where ease of passage through tissue, smooth tiedown, and precise knot placement are important

For suturing of the ligament to the periosteal surface we used PDO - a monofilament synthetic thread, made from polydioxanone, with an average resorption time $(60 \%$ of its tension after 28 days).

\section{Experimental part}

Materials and methods

Animal models

We randomised $6 \mathrm{NZW}$ rabbits for each study group (new graft group, $n=6$; ligament end group, $n=6$ ), having $3.75 \pm 0.06872 \mathrm{~kg}$ each. We respected the EU directives $63 / 2010$ and the Romanian ones 43/2014 with regards to animal studies during the entire procedure. The rabbits were held in proper individual boxes, having $4260 \mathrm{~cm} 2$ space. They were daily monitored and the boxes were cleaned 3 times a week, respecting a day/night cycle of $12 / 12 \mathrm{~h}$.

The room temperature was $20 \pm 2$ degrees $C$, the humidity level $45 \pm 10 \%$.

There were four persons who participated in realization of the experiment: main researcher, an assistant during the surgical intervention, veterinarian and the caretaker. The assistant prepared the materials for surgery and helped during the intervention (by retracting the edges of the incision and preparing the graft). All personnel wore protective equipment according to the internal regulations of the institution in which the procedures took place (the experimental animals shelter of the University of Medicine and Pharmacy, Cluj-Napoca).

Required materials: clipper, surgical drapes, antiseptic solutions, 1 and 5 mlL syringes, needles, surgical gowns, surgical masks, bonnets, sterile surgical kit, $2 \mathrm{~mm}$ sterile K-wire, drilling machine, 2,0 Vicril, 0 Ethilon, sterile compresses, normal saline.

\section{Surgical techniques}

The surgical intervention of anterior cruciate ligaments reconstruction began after the rabbits had been anaesthetized by an intramuscular injection (in the thigh not being operated on, using the lateral compartment). We used $1 \mathrm{mg} / \mathrm{kg}$ of Diazepam (Terapia®, Romania), 35 $\mathrm{mg} / \mathrm{kg}$ of Ketamine (Ketamin, CP Pharma ${ }^{\circledR}$, Germany) and $5 \mathrm{mg} / \mathrm{kg}$ of Xylazine (Xylazine Bio, Bioveta ${ }^{\circledR}$, Czech Republic). At the incision site we also administered local anaesthesia by a subcutaneous injection of Bupivacaine $0.5 \%$ (Bupivacaine Abbot Laboratories ${ }^{\circledR}$, USA). During the surgery the rabbits were breathing spontaneously. The knee and leftcalf were shaved, the skin was prepared with iodine solution and isolated with surgical drapes.

The surgical intervention took place under sterile conditions. The rabbits were put in a supine position and covered with surgical drapes. The knee and left calf remained exposed. A lateral thigh incision was made on the lateral aspect of the thigh, and the tendon of the tensor digitorum longi was exposed. From this tendon we harvested a $25 \mathrm{~mm}$ graft and 1,5-2 $\mathrm{mm}$ in diameter. A pulling string was added at each end of the graft. We also performed an incision on the median line of the anterior aspect of the knee, also called a median pararotulian arthrothomyand we laterally dislocated the patella. In the reference study group we cut the $A C L$ with a $22 \mathrm{G}$ needle. In the study group the femoral $A C L$ insertion is cut. A tibial and femoral tunnel is made with the help of a $2 \mathrm{~mm} \mathrm{~K}$ wire in the insertion site of the ACL. The graft is inserted and fixed both to the femur and the tibia with the help of a

periosteal suture, using a No.2 PDO suture thread. Each tissue layer is sutured (the arthrotomy with Vicryl and the teguments with Ethilon).

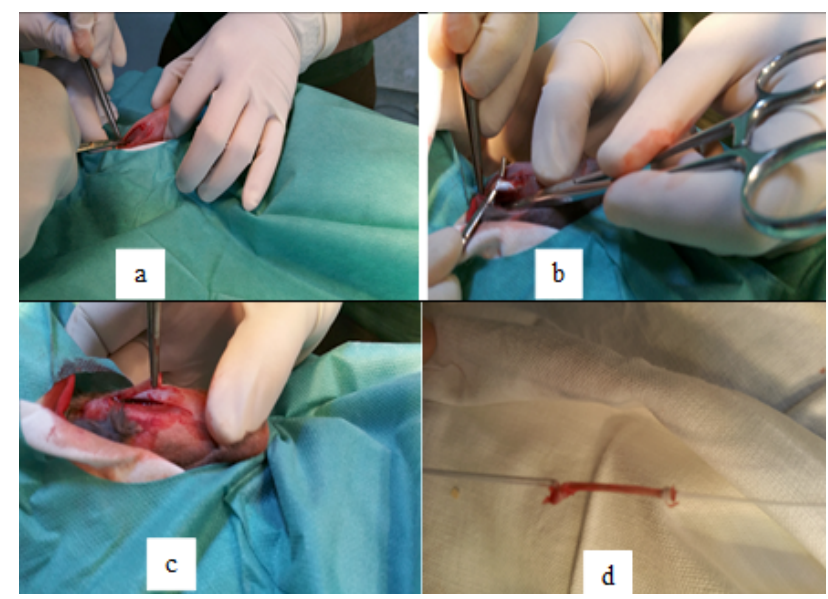

Fig. 4. The cutting and preparing of the neoligament ( $A$ - incision on the lateral part of the thigh, B - EDL tendon highlight, $C$-cutting of the tendon, $\mathrm{D}$ - neoligament preparation, $25 \mathrm{~mm}$ length, 1.5-2 $\mathrm{mm}$ diameter)
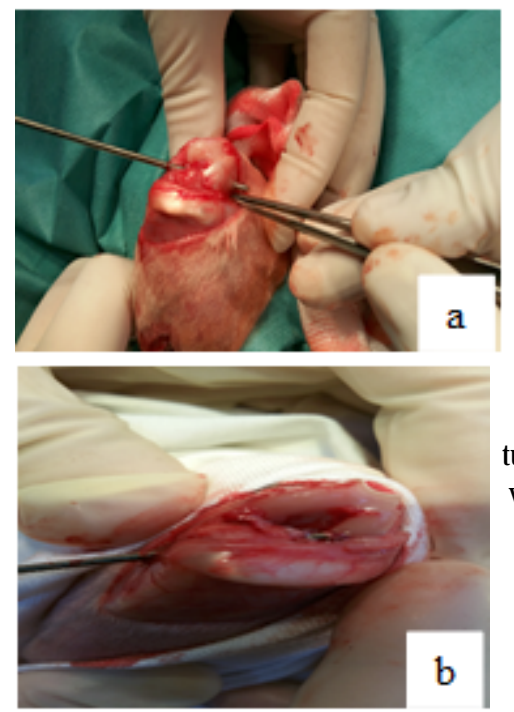

Fig. 5. Fixing the neoligament: a) femoral tunnelling using the $2 \mathrm{~mm} \mathrm{~K}$ wire at the old $\mathrm{ACL}$ site; $b$ ) tibial tunnelling at the old ACL site; c) positioning, tensioning and fixing the neoligament.

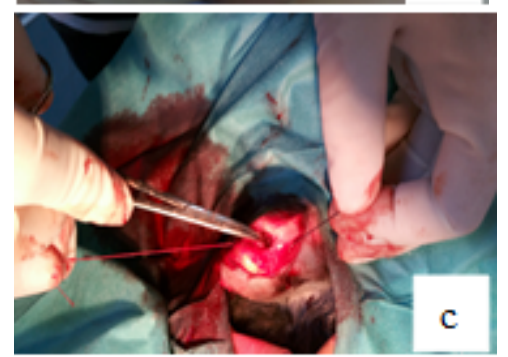

Postoperative care

Postoperatively, the animals received the following medication: $2 \mathrm{mg} / \mathrm{kg}$ of Tramadol Hydrocloride (Mabron $\AA$, Medochemie LTD, Cyprus) for 7 days, $0.5 \mathrm{mg} / \mathrm{kg}$ of Meloxicam (Melovem ${ }^{\circledR}$, Dopharma, Romania) every day for 5 days, $10 \mathrm{mg} / \mathrm{kg}$ of Enrofloxacin (Enrofloxacin ${ }^{\circledR}$, Pasteur Institute, Romania) for 7 days. The animals were daily examined and the surgical incision cared for. In order to harvest the grafts, one half from each of the two groups was sacrificed on week 3 and 6 . For this, anaesthesia was induced following the above-mentioned protocol and a lethal dose of Potassium Chloride was administered. The death was confirmed by the absence of respiratory movements and heart activity. We studied the presence of inflammatory reaction around the sutures used to anchor the neoligament to the periosteum and also the suture resistance. 


\section{Results and discussions}

The macroscopic aspect of the graft at 3 and 6 weeks after surgery are shown in figure 6 . The differences between the surgical techniques used, respectively the classic technique surgery (excision $\mathrm{ACL}$ ) and augmentation technique surgery (femoral excision of $\mathrm{ACL}$ and preserving one edge of the torn ligament) are visible at the macroscopic level.
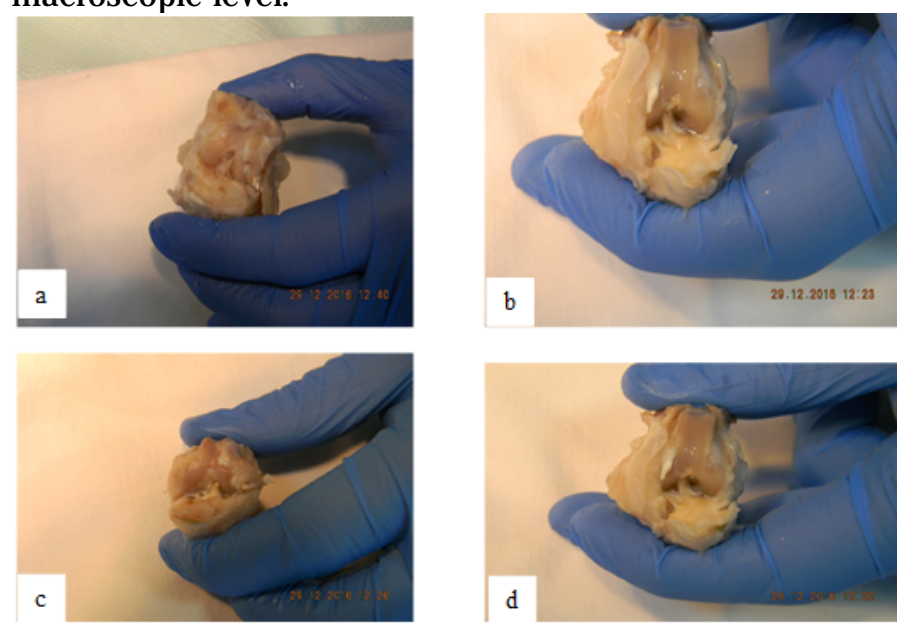

Fig. 6. The macroscopic aspect of the graft : a) 3 weeks after

classic technique surgery; b) 3 weeks after augmentation technique surgery; c) 6 weeks after classic technique surgery; d) 6 weeks after augmentation technique surgery

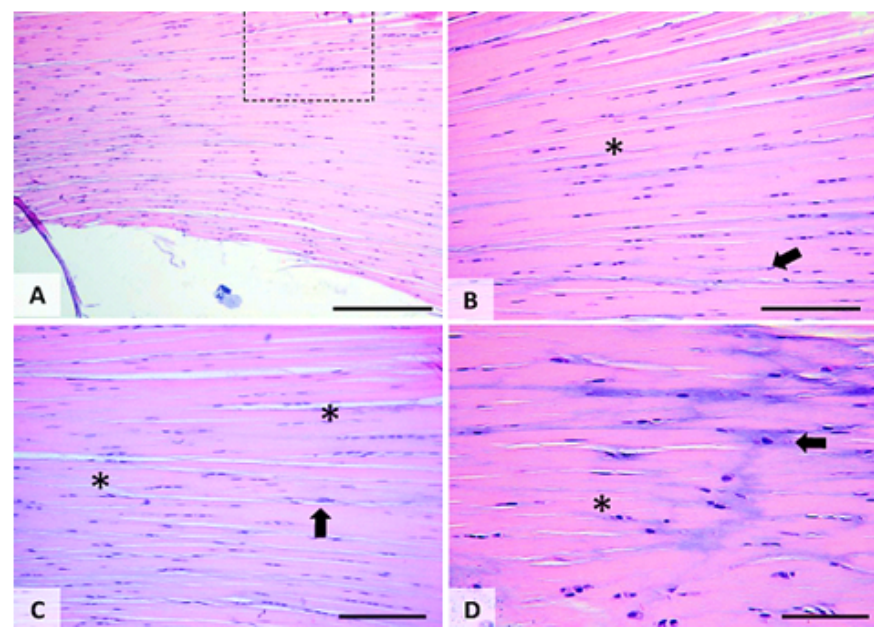

Fig. 7. The histopathology exam of the crossed normal ligaments $H \& E$, obx10 for Image $A$ (scale $=400 \mu \mathrm{m}$ ), obx20 for Image $B$ and C (scale $=200$ )

A complex histopathological analysis was made on the crossed ligaments. The results are shown in figures 7-13. We compared the neoligament integration following the classic ligamentoplasty technique and an augmentation technique with a femoral excision of the anterior crossed ligament.

In figure 7, the general view of a normal cruciate ligament could be observed in image 7A. This view didn't have any significant histologic modifications. In image 7B appear a histologic detail of the square delimited area from the A image. One can observe the normal cellular structure (arrow) and the parallel orientation of the collagen fibres (star). The images 7C and 7D have shown the histologic details of the cruciate ligament. Note the normal cellular structure and the presence of the thick collagen fibres in parallel orientation (star). The arrow indicates basophils agglomerations with a confluenttendency associated with a minimum cartilaginous metaplasia (cellular orientation in circular groups which mimes the aspect of a spare chondroitarea.)
In figure 8, the image 8A surprises the ensemble aspect of a cruciate ligament, marked by the presence of a marginal inflammatory reaction. The image $8 \mathrm{~B}$ presents $\mathrm{a}$ histological detail of the square marked zone from the $8 \mathrm{~A}$ image. It can be noticed the clear demarcation of the inflammatory reaction (arrow) from the bordered tissue (star). The images 8C and 8D have shown the histological details of the lesion. The stars indicate the peripheral normal tissues.

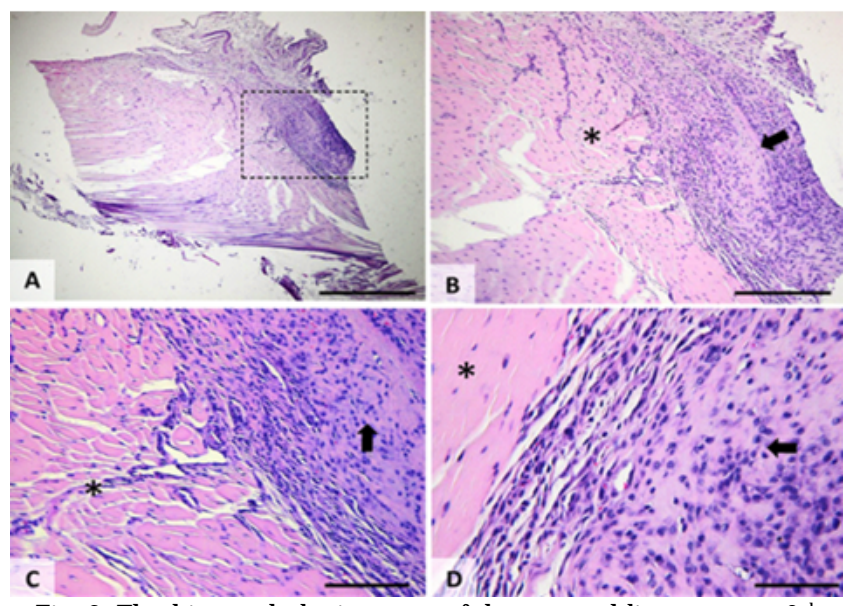

Fig. 8. The histopathologic exam of the crossed ligaments at $3^{\text {rd }}$ week after surgery on rabbits who underwent the classic technique. $H \& E$, obx10 for the image $A$ (scale $=400 \mu \mathrm{m}$ ) obx20 for $B$ and $C($ scale $=200 \mu \mathrm{m})$, images $($ scale $=100 \mu \mathrm{m})$ respectively obx40 for the image $D($ scale $=100 \mu \mathrm{m})$

Image 9A represents the ensemble aspect of the cruciate ligament, marked by the massive ligament inflammation and the villosa hyperplasia of the bordered synovial membrane. The image $9 B$ represents a histologic detail of the rectangle marked zone from the image $9 \mathrm{~A}$. The images $9 C$ and $9 D$ represent histological details of the lesions, characterized by massive inflammatory infiltrate (mixed neutrophilic and mononuclear) (the arrow from the image 9D) (rich vascularisation). The star from the image 9D indicates the aspect of the inflammatory tissue.

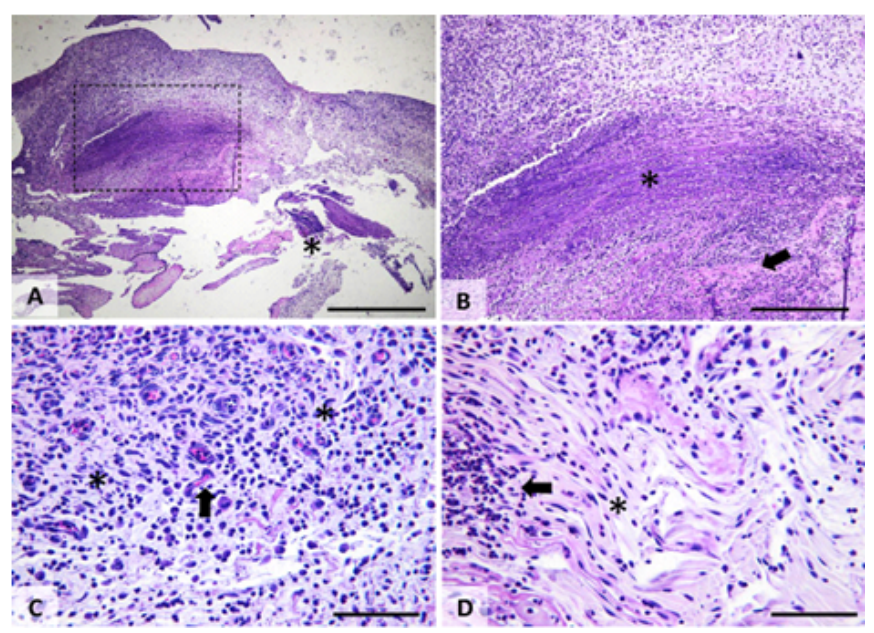

Fig. 9. The histopathologic exam of the crossed ligaments the $3^{\text {rd }}$ week after surgery in rabbits who underwent augmentation

(femoral excision of anterior crossed ligaments and the preservation of the ligament end). $H \& E, o b \times 4$ for the image $A$

$($ scale $=1000 \mu \mathrm{m})$, ob $\times 10$ for the image $B($ scale $=400 \mu \mathrm{m})$,

respectively ob $\times 40$ for the image $C \& D($ scale $=100 \mu \mathrm{m})$

The image $10 \mathrm{~A}$ captures the overall picture of the crossed ligament, marked by the abundant presence of the vascularized adult scar tissue (star). We can observe cartilaginous metaplasia (detailed in image 10B and 10D images, where the arrows indicate the chondrocyte specific 


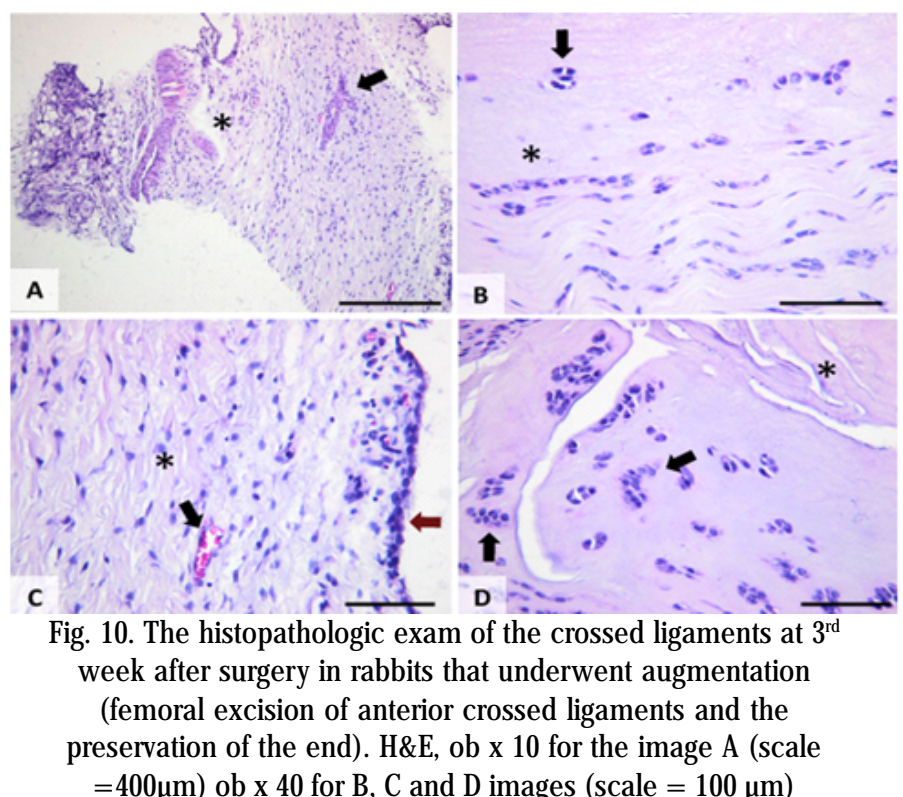

disposal of the cells. Marginally, the vascular adult scar tissue (marked with a star and an arrow in the image 10C) is delimited by synoviocyte (the red arrow from the image 10C)

The image $11 \mathrm{~A}$ captures the overall aspect of the crossed ligament, marked by the abundance of the regenerative scar tissue and the presence of the multiple synovial proliferations with a vilosity-like aspect (arrows). The image 11B shown a histological detail of the fingerlike synovial proliferation, which contains a fibrous skeleton delimited through sinoviocytes. The images 11C and 11D present the histological details of the fibrocartilaginous outbreaks and the adjacent tissues.

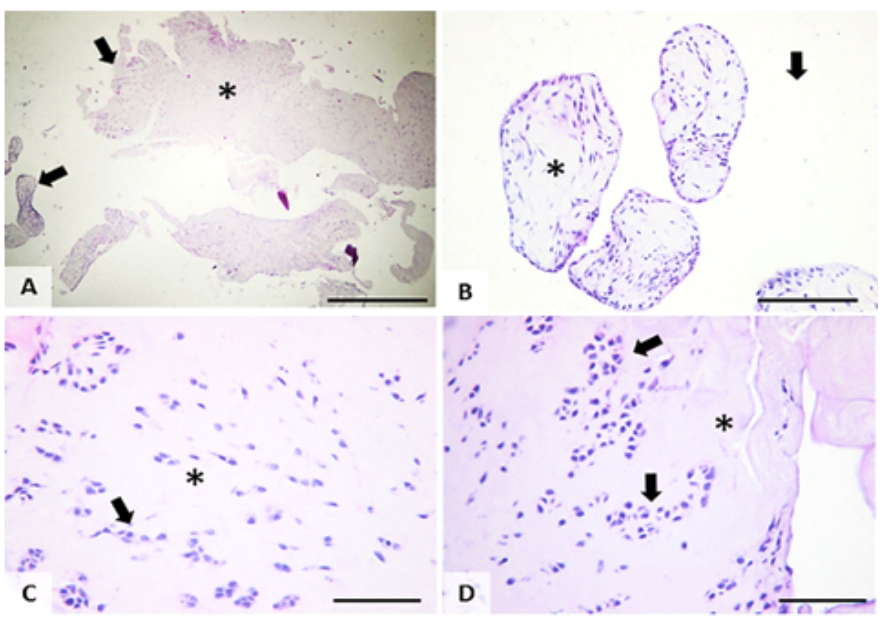

Fig. 11. the histopathologic exam of the crossed ligaments 6 weeks after surgery on rabbits who underwent the classic technique. $H \& E, o b \times 4$ for the image $A$ (scale $=1000 \mu \mathrm{m}$ ), obx10 for the image $B($ scale $=400 \mu \mathrm{m})$, respectively ob $\times 40$ for the images $C$ and $D$ ( $\mathrm{scale}=100 \mu \mathrm{m}$ )

The image $12 \mathrm{~A}$ and image $12 \mathrm{~B}$ captures the overall image of the crossed ligament, marked by the abundance of the regenerative scar tissue, intensively vascularized (star) with vilosity arrangement (black arrow). The images $12 \mathrm{C}$ and 12D shown the histological details of the tissues which are adjacent to the scar zone, characterized by an orderly disposal of the cells through the adult collagen fibres (star) (image 12D). In the image $12 \mathrm{C}$ there can be noticed the cross line between the scar tissue (arrow) and the tendon without significant modifications (star).

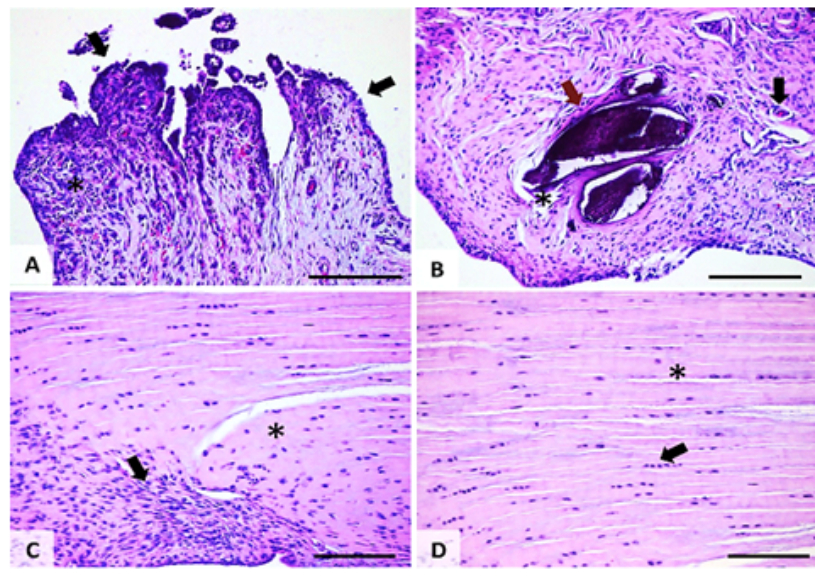

Fig. 12. The histopathologic exam of the crossed ligaments 3 weeks after the surgery on rabbits who underwent the classic technique. $H \& E$, ob $\times 10$ for the image $A(s c a l e=400 \mu \mathrm{m})$, ob $\times 40$ for the images $B, C$ and $D($ scale $=100 \mu \mathrm{m})$.

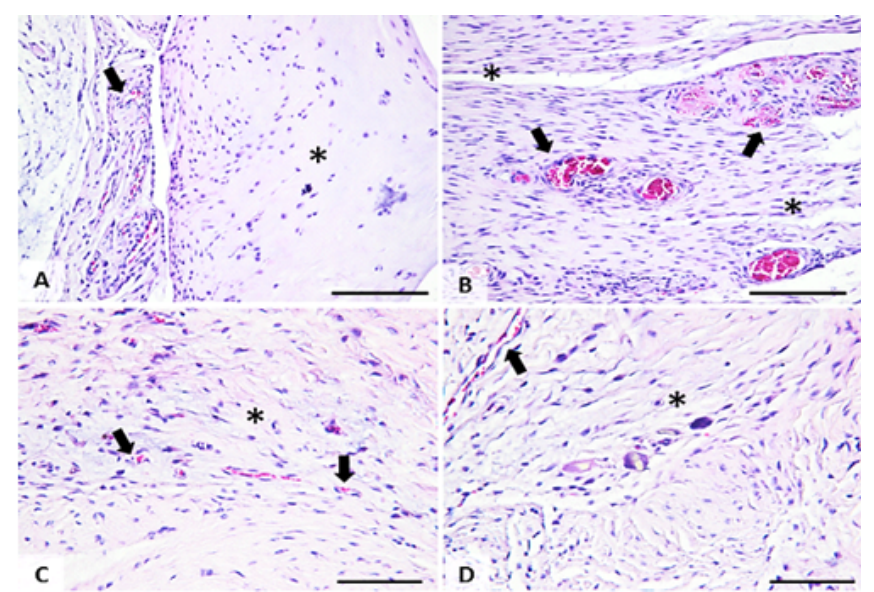

Fig. 13. The histopathologic exam of the crossed ligaments 6 weeks after surgery of rabbits who underwent the augmentation

(femoral excision of anterior crossed ligaments and the preservation of the end); $H \& E$, ob $\times 20$ for the image $A$ (scale =

$200 \mu \mathrm{m}), \mathrm{ob} \times 40$ for the images $B, C$ and $D($ scale $=100 \mu \mathrm{m})$

The image 13A captures the overall aspect of the crossed ligament marked by the presence of the massive cartilaginous metaplasia (star), and by the granulation tissue well vascularized (arrow). The images 13B, 13C and 13D capture the details of the intense vascular bed (arrows) of the granulation tissue in different maturation phases.

\section{Conclusions}

In this study we compared the neoligament integration following the classic ligamentoplasty technique and an augmentation technique with a femoral excision of the anterior crossed ligament, saving the end and inserting the neoligament using the same technique. We studied the importance of the remaining end for the neoligament integration.

Three weeks after using the augmentation technique, we noticed the abundance of the inflammatory tissue and of the intense vascular tissue, multiple mineralization zones and the appearance of the adult scar tissue. Six weeks after using the classic techniques, we noticed the appearance of the scar regenerative tissue, with mineralization points dispersed in the highly vascular scar tissue. Six weeks after using the augmentation technique a regenerative scar tissue appeared in the form of a highly vascular granulative tissue.

The results show that, on a long term basis, by saving the ligament end, there is no advantage as far as the 
integration, revascularization and cellular proliferation is concerned. By using the augmentation technique that implies saving the ligament end, some changes specific to the neoligament integration appeared earlier ( 3 weeks compared to 6 weeks when using the classic technique). The results already published are not consistent, with some of the studies obtaining comparable results using the two techniques. Other studies suggested an important role of saving the ligament end. He interpreting of our results poses some difficulties because of the small number of specimens studied. But nonetheless, should be taken into consideration for further research.

With regard to the periosteal fixing material we found a good biocompatibility. The suture thread did not trigger a local inflammatory reaction and its resistance was maintained until full graft fixation.

\section{References}

1.MICULESCU, F.; BOJIN, D.; CIOCAN, L. T.; et al., Experimental researches on biomaterial-tissue interface interactions, J OURNAL OF OPTOELECTRONICS AND ADVANCED MATERIALS Volume: 9 Issue: 11 Pages: 3303-3306 Published: NOV 2007

2.BITA, ANA-IULIA; STAN, G. E.; NICULESCU, M.; et al., Adhesion evaluation of different bioceramic coatings on $\mathrm{Mg}$-Ca alloys for biomedical applications, JOURNAL OF ADHESION SCIENCE AND TECHNOLOGY Volume: 30 Issue: 18 Pages: 1968-1983 Published: 2016

3.ANTONIAC, IULIAN; NEGRUSOIU, MIHAI; MARDARE, MIHAl; et al., Adverse local tissue reaction after 2 revision hip replacements for ceramic liner fracture A case report, MEDICINE Volume: 96 Issue: 19 Article Number: e6687 Published: MAY 2017

4.BENEA, HOREA; TOMOAIA, GHEORGHE; SORITAU, OLGA; et al., A Review on the Reconstruction of Articular Cartilage Using Collagen Scaffolds, ROMANIAN BIOTECHNOLOGICAL LETTERS Volume: 21 Issue: 4 Pages: 11720-11728 Published: JUL-AUG 2016

5.MARINESCU, R.; ANTONIAC, I.; LAPTOIU, D.; et al., Complications Related to Biocomposite Screw Fixation in ACL Reconstruction Based on Clinical Experience and Retrieval Analysis, Mat. Plast., 52, no. 3, 2015, p.340-344

6.BOTEZ, P.; SIRBU, P.; SIMION, L.; et al., Application of a biphasic macroporous synthetic bone substitutes $\operatorname{CERAFORM(A~(R)):~clinical~}$ and histological results, EUROPEAN JOURNAL OF ORTHOPAEDIC SURGERY AND TRAUMATOLOGY Volume: 19 Issue: 6 Pages: 387395 Published: AUG 2009

7.RIVIS, M.; PRICOP, M.; TALPOS, S.; et al., Influence of the Bone Cements Processing on the Mechanical Properties in Cranioplasty, Rev. Chim. (Bucharest), 69, no. 4, 2018, p. 990-993

8.ANTONIAC, IULIAN; SINESCU, COSMIN; ANTONIAC, AURORA, Adhesion aspects in biomaterials and medical devices, JOURNAL OF ADHESION SCIENCE ANDTECHNOLOGY Volume: 30 Issue: 16 Special Issue: SI Pages: 1711-1715 Published: AUG 172016

9.GRECU, D.; ANTONIAC, I.; TRANTE, O.; et al., Failure Analysis of Retrieved Polyethylene Insert in Total Knee Replacement, Mat. Plast. 53, no. 4, 2016, p. 776-780
10.RAU, JULIETTA V.; ANTONIAC, IULIAN; CAMA, GIUSEPPE; et al., Bioactive Materials for Bone Tissue Engineering, BIOMED RESEARCH INTERNATIONAL Article Number: 3741428 Published: 2016

11.STANCU, IZABELA-CRISTINA; DRAGUSIN, DIANA MARIA; VASILE, EUGENIU; et al., Porous calcium alginate-gelatin interpenetrated matrix and its biomineralization potential, J OURNAL OF MATERIALSSCIENCEMATERIALS IN MEDICINE Volume: 22 Issue: 3 Pages: 451-460 Published: MAR 2011

12.RUSEN, EDINA; MOCANU, ALEXANDRA; MARCULESCU, BOGDAN; et al., Obtaining complex structures starting from monodisperse poly(styrene-co-2-hydroxyethylmethacrylate) spheres, COLLOIDS AND SURFACES A-PHYSICOCHEMICAL AND ENGINEERING ASPECTS Volume: 375 Issue: 1-3 Pages: 35-41 Published: FEB 52011

13.PETREUS, TUDOR; STOICA, BOGDAN ALEXANDRU; PETREUS, OANA; et al., Preparation and cytocompatibility evaluation for hydrosoluble phosphorous acid-derivatized cellulose as tissue engineering scaffold material, JOURNAL OF MATERIALS SCIENCEMATERIALS IN MEDICINE Volume: 25 Issue: 4 Pages: 1115-1127 Published: APR 2014

14.NICULESCU, M.; ANTONIAC, A.; VASILE, E.; et al., Evaluation of Biodegradability of Surgical Synthetic Absorbable Suture Materials: An In Vitro Study, Mat. Plast., 53, no. 4, 2016, p: 642-645

15.EARAR, K.; GRADINARU, S.; PARIZA, G.; et al., Effect of the Sterilization Procedures of Different Surgical Meshes for Abdominal Surgery, Rev. Chim. (Bucharest), 68, no. 8, 2017, p. 1868-1873

16.MAVRODIN, C. I.; PARIZA, G.; ION, D.; et al., Abdominal Compartment Syndrome - A Major Complication of Large Incisional Hernia Surgery, CHIRURGIA Volume: 108 Issue: 3 Pages: 414-417 Published: MAY-JUN 2013

17.PARIZA, G.; MAVRODIN, C.I.; ANTONIAC, I., Dependency Between the Porosity and Polymeric Structure of Biomaterials Used in Hernia Surgery and Chronic Mesh - infection, Mat. Plast., 52, no. 4, 2015, p: 484-486

18.AHN JH, W ANG JH, LEE YS, et al. Anterior cruciate ligament reconstruction using remnant preservation and a femoral tensioning technique: clinical and magnetic resonance imaging results. Arthroscopy. 2011;27:1079-89.

19.GULOTTA LV, RODEO SA, Biology of autograft and allograft healing in anterior cruciate ligament reconstruction . Clin Sport Med 2007; 26:509-24

20.GREVE H, SCHUMANN U, GALLEGO R, DITTRICH H. Intracutaneous skin suture with a resorbable synthetic monofilament suture. Langenbecks Arch Chir. 1986;368(1):57-63.

21.HONG L., LI X., ZHANG H. Anterior cruciate ligament reconstruction with remnant preservation: A prospective, randomized controlled study. Am J Sports Med. 2012;40:2747-2755.

22.LEI Z, KAN J , HAO C, MAI Z, J ingping B A Comparative Animal Study of Tendon Grafts Healing After Remnant-Preserving Versus Conventional Anterior Cruciate Ligament Reconstruction.2016 Sept 26; 22:3426-3437.

Manuscript received: 15.10 .2018 